\title{
Simulation of a-Si PV System Linked to the Grid by DC Boost and Three-Level Inverter Under Cloud Scope
}

\author{
L. Fialho $^{1,2}$, R. Melício ${ }^{1,2(区)}$, V.M.F. Mendes ${ }^{2,3}$, and M. Collares-Pereira ${ }^{2}$ \\ ${ }^{1}$ IDMEC/LAETA, Instituto Superior Técnico, Universidade de Lisboa, Portugal \\ ${ }^{2}$ Universidade de Évora, Évora, Portugal \\ ruimelicio@gmail.com \\ ${ }^{3}$ Instituto Superior of Engenharia de Lisboa, Lisbon, Portugal
}

\begin{abstract}
This paper is about a PV system linked to the electric grid through power converters under cloud scope. The PV system is modeled by the five parameters equivalent circuit and a MPPT procedure is integrated into the modeling. The modeling for the converters models the association of a DC-DC boost with a three-level inverter. PI controllers are used with PWM by sliding mode control associated with space vector modulation controlling the booster and the inverter. A case study addresses a simulation to assess the performance of a PV system linked to the electric grid. Conclusions regarding the integration of the PV system into the electric grid are presented.
\end{abstract}

Keywords: PV system $\cdot$ DC-DC boost $\cdot$ Three-level inverter $\cdot$ Simulation

\section{Introduction}

The increment on the use of scarce fossil-fuel sources, the society wariness about the anthropogenic gas emissions and the increasing energy demand have strongly impelled the development of the use of renewable energy sources during the last decades [1]. For instance, the growth of the annual market regarding exploitation of solar energy is an evidentiary fact during the last decade. Particularly, a growing expansion is to be expected over the coming decade in what regards the deployment of photovoltaic (PV) systems.

The European Commission has launched a line of attack for the Europe to become a highly energy-efficient and a low-carbon economy with a set of proposals to create a new Energy Policy for Europe, reducing the anthropogenic gas emissions by $20 \%$ by 2020 and $50 \%$ until 2050, raising the overall share of conversion from renewable energy sources. Solar energy exploitation is expected to be significant on the European Energy Policy. Also, European Commission points out a future significant advance towards a more active role of the consumer by the implementation of the concept of smart grid (SG), improving integration into the grid for renewable energy sources and increasing energy efficiency. An advance thought to have a significant impact on mitigation of anthropogenic gas emissions, job and technology development [2].

A PV system directly converts solar energy into electric energy. The main device of a PV system is the solar cell. Solar cells are grouped to form PV arrays. An array is either a panel or a set of panels connected in series or parallel to form large PV systems. Simulation of PV systems is vital to assist in exporting energy, anticipating 
bad performances and deciding convenient measures to avoid malfunctions and my significant benefit in real-time application from cloud-based solutions.

Power electronic converters have been developed for assisting in the integration of renewable energy conversion into the electric grid. Historically, low power PV systems use single-phase inverters, but in three-phase grid linking the use of only one single-phase inverter produces unwanted imbalance between the phase currents due to the injection of energy into only one phase of the grid. As reported in [3] a maximum power of $4.6 \mathrm{~kW}$ with $10 \%$ of tolerance is possible to link to only one phase of a three-phase grid. Three single-phase inverters are needed for linking power greater than $5 \mathrm{~kW}$ to ensure a convenient balanced energy distribution between the phases.

\section{Relationship to Cloud-Based Solutions}

A Cloud-based solution is significant support for launching a line of attack for a future highly energy-efficient management of energy conversion and usage. As the global energy demand increases with the growing world population, alternative sources of energy turn out to be attractive for exploitation in what regards a sustainable society's development. Within this attractive exploitation, the renewable energy from PV systems exploitation is considered one promising and reliable energy source for distributed generation (DG). DG and the increase usage of electric energy, for instances, the expected significant usage of electrical vehicles, will drive upcoming concerns on nowadays electrical grid about the ability to encompass with the future. So, a hatching thought about the electric grid is needed and the SG conception is on the way. A SG will benefit from cloud-based solutions allowing data interchange between end users and producers for transparency on energy consumption and on energy conversion of other forms of energy into electric energy. A Cloudbased solution allows the wanted consumer commitment in the management within the SG scope. The SG will be a source of information able to interact with other kinds of data, not only monitoring the flow of electric energy, but also an entire set of environments, leading to a foreseen increase data to be processed by SG management systems. So, the SG architecture has to be implemented with ensured security and reliability. A layered framework is one option gathering information about the SG components offering an awareness of the behavior, enabling people or machines to act accordingly over a services platform. The engineered software framework can be transposed to a Cloud architecture system, taking advantages of the existing internet cloud services to process with reduced operational costs the data storage and data transfer in real-time with reduced operational costs. For instance, as depicted in Fig. 1 for the PV system in study in this paper. This framework facilitates the integration of sensors and actuators with bidirectional data exchange [4], [5], [6], allowing real-time simulations speeding up the integration PV system energy into Smart Grid.

\section{$3 \quad$ Modeling}

The solar cell is modeled by the five parameter equivalent circuit: a photo electric current controlled source giving $I_{s}$, a shunt single-diode $D$ draining the current $i_{D j}$, 
a shunt resistance $R_{p}$ draining the leakage current $I_{p}$, a series resistances $R_{s}$ delivering the output current $I_{j}$ of the cell having the output voltage $V_{j}$. As a normal assumption, assume that the cells associated within the module are equally subjected to the same irradiance and the junctions are at the same temperature, then the equivalent circuit for the PV module is same of the cell, but with a suitable numerical transformation in the values for the parameters. The PV system under study is formed by a PV module, a DC-DC boost and a three-level power inverter linking the system to an electric grid. The PV system is shown in Fig. 1.

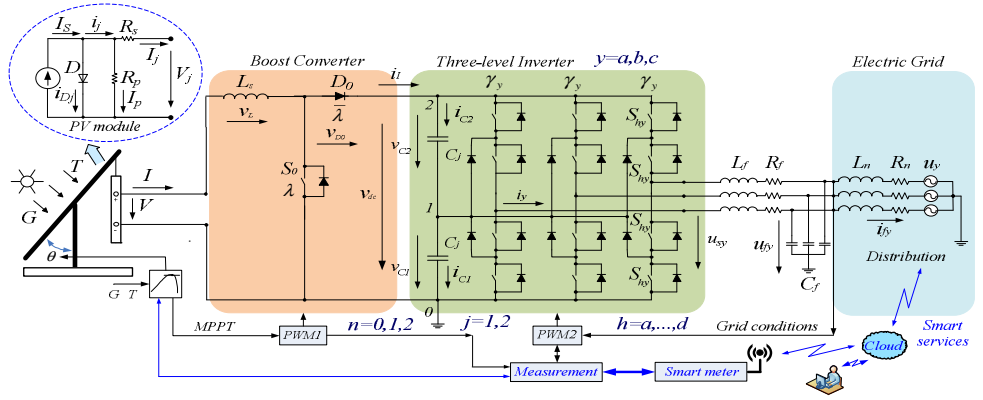

Fig. 1. PV system linked to the electric grid through power converters

In Fig. 1, $G$ is the solar irradiance, $T$ is the cell p-n junction temperature in $[\mathrm{K}]$ and the current $i_{j}[2]$ is given by:

$$
i_{j} \equiv I_{j}+\left(V_{j}+R_{s} I_{j}\right) / R_{p}
$$

where $j$ is a condition index: $j=o c$ identifies open circuit condition; $j=s c$, short circuit condition, $j=m x$, maximum power point (MPP) condition. From (1), finding $R_{s}$ at short circuit and at MPP conditions, holds the equations [2] given by:

$$
V_{o c} \frac{i_{m x}-I_{m x}}{I_{m x}}-\frac{V_{m x} i_{o c}}{I_{m x}}-V_{o c} \frac{i_{s c}-I_{s c}}{I_{s c}}=0
$$

The MPP of a PV system depends on $G$ and $T$, at the MPP the conversion is at the highest efficiency and satisfies the relation [2] given by:

$$
\gamma R_{p} i_{m x}^{s c}\left(V_{m x}-R_{s} I_{m x}\right)\left(e_{m x}+1\right)+V_{m x}-I_{m x}\left(R_{s}+R_{p}\right) e_{s c}^{m x}=0
$$

The input parameters for the MPPT algorithm are the values of the voltage and the current of the PV system. The condition to be satisfied is given by $\partial P / \partial V=0$, i.e., if the condition is met, then the algorithm has found the MPP point. But typically in practice the algorithm iterates around that condition until eventually converges. The iteration procedures are as follows; if $\partial P / \partial V>0$, an incremental adjustment is set in order to increase the out voltage, i.e., in the direction of the MPP; if $\partial P / \partial V<0$, an adjustment is set in order to decrease the out voltage in the direction of the MPP [7]. 
The General Algebraic Modeling System (GAMS) is used to code a mathematical programming problem to identify the five parameters for the equivalent circuit of the PV system, using data information from the tests of open circuit, short circuit, maximum power point (MPP) conditions. The free solver COUENNE-Convex Over and Under Envelopes for Nonlinear Estimation for global optimization is used as a convenient option, due to the involvedness on the problem of identification of parameters [2]. The DC-DC boost converter has one unidirectional commanded IGBT, $S_{0}$. This converter is linked between the PV module and capacity banks, which in turn is linked to a three-level inverter. The modeling for the DC-DC boost converter is given by the switching variable $\lambda$ used to identify the state of $S_{0}$ and the switching variable $\bar{\lambda}$ used to identify the state of the diode $D_{0}$. These variables have to satisfy the switching condition [8] given by:

$$
\left\{\begin{array}{l}
\lambda=1 \text { and } \bar{\lambda}=0\left(S_{0}=1 \text { and } D_{0}=0\right) \\
\lambda=0 \text { and } \bar{\lambda}=1 \quad\left(S_{0}=0 \text { and } D_{0}=1\right)
\end{array}\right.
$$

The module current $I$ is modeled by the state equation given by:

$$
d I / d t=1 / L_{s}\left[\mathrm{~V}-\bar{\lambda}\left(v_{D 0}+v_{d c}\right)\right]
$$

where $v_{D 0}$ is the diode forward voltage at direct current and $v_{d c}$ is the voltage at the capacity banks.

The three-level inverter is linked between capacity banks and a second order filter, which in turn is linked to the electric grid, modeled by a three-phase active symmetrical circuit. The DC-AC inverter is a three-level inverter, having twelve unidirectional commanded IGBT identified by $S_{h y}$, used as an inverter. The groups of four IGBT's linked to the same phase constitute the leg $y$ of the inverter with $y \in\{a, b, c\}$ [9]. The converter has $p=3$ levels. For the balance control strategy, the switching voltage level variable $n_{y}$ which ranges from 0 to $(p-1)$ is used to identify the state of the IGBT $h$ in the leg $y$ of the inverter establishing the switching function of each IGBT. The index $h$ with $h \in\{a, b, c, d\}$ identifies the IGBT. The three conditions to be satisfied for the switching voltage level variable of a leg $y$, at each level [9], are given by:

$$
n_{y}=\left\{\begin{array}{cccc}
2, & \left(S_{a y} \text { and } S_{b y}\right)=1 & \text { and } & \left(S_{c y} \text { or } S_{d y}\right)=0 \\
1, & \left(S_{b y} \text { and } S_{c y}\right)=1 & \text { and } & \left(S_{a y} \text { or } S_{d y}\right)=0 \\
0, & \left(S_{c y} \text { and } S_{d y}\right)=1 & \text { and } & \left(S_{a y} \text { or } S_{b y}\right)=0
\end{array} \quad y \in\{a, b, c\}\right.
$$

The inverter output voltage $u_{s y}$ in function of $v_{d c}$ [9] is given by:

$$
u_{s y}=\frac{1}{6}\left(2 n_{y}-\sum_{\substack{j=a \\ j \neq y}}^{c} n_{j}\right) v_{d c} \quad y \in\{a, b, c\} ; n \in\{0,1,2\}
$$


The voltage at the capacity banks $v_{d c}$ appearing in (5) is a function of the electric charge stored or discharged from the capacitors by the action of the control of the converters. Hence, the state equation for this voltage is a function of the currents each capacitor $i_{c j}[9]$ and is given by:

$$
\frac{d v_{d c}}{d t}=\sum_{j=1}^{p-1} \frac{1}{C_{j}} i_{c j} \quad j \in\{1, \ldots, p-1\}
$$

The current $i_{c j}$ [9] is given by:

$$
i_{c j}=i_{I}-\sum_{y=a}^{c} \delta_{n y} i_{y} \quad j \in\{1, \ldots, p-1\}
$$

where the auxiliary variable $\delta_{n y}[9]$ is given by:

$$
\delta_{n y}=\left\{\begin{array}{ll}
0 & j>n_{y} \\
1 & j \leq n_{y}
\end{array} \quad n \in\{0,1,2\} ; \quad j \in\{1, \ldots, p-1\}\right.
$$

The electric grid is modeled by an equivalent three-phase active symmetrical circuit, having a resistance and an inductance in series. Hence, for the electric current injected into the electric grid the state equation is given by:

$$
\frac{d i_{f y}}{d t}=\frac{1}{L_{n}}\left(u_{f y}-R_{n} i_{f y}-u_{y}\right)
$$

where $L_{n}$ and $R_{n}$ are the electrical grid inductance and resistance, respectively, $u_{f y}$ is the voltage at the filter, $u_{y}$ is the voltage at the electric grid.

\section{Control Method}

The three-level inverter is a variable structure due to on/off switching states of the IGBT's. PI control and PWM by space vector modulation associated with sliding mode is used for controlling the inverter with the output vectors levels 0,1 and 2 in the $\alpha \beta$ plane [9] shown in Fig. 2 .

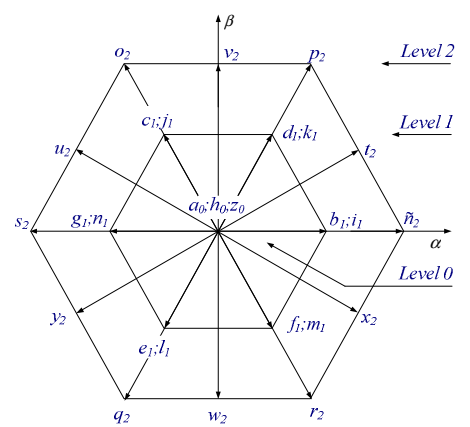

Fig. 2. Output space vectors for modeling of the three-level inverter 
The sliding mode control strategy is an option known by the advantage of having attractive considerable robustness to parametric uncertainties [9] due to partial shading or electric grid disturbances. Sliding mode control is particularly attractive in systems with variable structure, such as inverters, ensuring the choice of space vectors. The aim is to let the system slide along a predefined sliding surface $A\left(e_{\alpha \beta}, t\right)$ by changing the system structure. All transistors have a physical limitation due to the switch of finite frequency. So, an error exists between the control and the reference $e_{\alpha \beta}$ values. The sliding along the surface $A\left(e_{\alpha \beta}, t\right)$ is ensured by a state trajectory near the surfaces satisfying the condition [9] given by:

$$
A\left(e_{\alpha \beta}, t\right) \frac{d A\left(e_{\alpha \beta}, t\right)}{d t}<0
$$

The control for the MPPT is a simple adjustments over the DC-DC boost converter in order to follow the condition given by $\partial P / \partial V=0$.

\section{Case Study}

The mathematical modeling for the solar cell with single-diode, shunt and series resistances, for the MPPT algorithm and for the PV system with the DC-DC boost and the three-level topology is implemented in Matlab/Simulink without the use of Power System Blockset. This case study presents a simulation concerned with the data measured [11] from PV a-Si solar modules Kaneka KA58 provided in [10]. The irradiation is $800 \mathrm{~W} / \mathrm{m}^{2}$, module temperature is $13{ }^{\circ} \mathrm{C}$ and nominal $\mathrm{AC}$ power is $6 \mathrm{~kW}$. The data for the a-Si solar module Kaneka KA58 at STC [12] are shown in Table 1. Table 2 shows the data results for the PV modelling simulation.

Table 1. Data for the Kaneka KA58 solar module at STC

\begin{tabular}{ccccccc}
\hline Technology & $V_{m}^{*}$ & $I_{m}^{*}$ & $V_{o c}^{*}$ & $I_{s c}^{*}$ & $\beta_{o c}$ & $\alpha_{s c}$ \\
\hline Amorphous & $63 \mathrm{~V}$ & $0.92 \mathrm{~A}$ & $85 \mathrm{~V}$ & $1.12 \mathrm{~A}$ & $-206 \mathrm{mV} /{ }^{\circ} \mathrm{C}$ & $1.3 \mathrm{~mA} /{ }^{\circ} \mathrm{C}$ \\
\hline
\end{tabular}

The current injected into the grid is shown in Fig. 3.

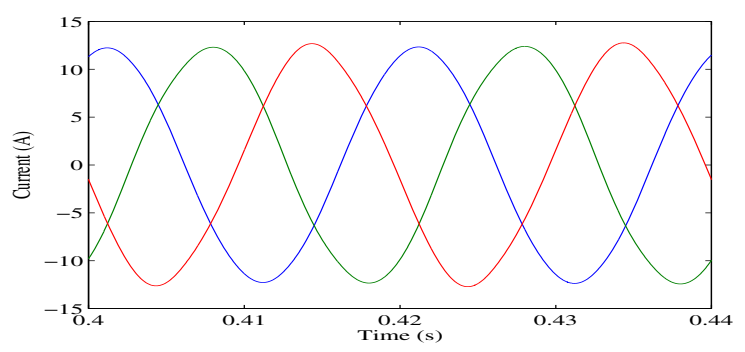

Fig. 3. Current injected into the electric grid 
The total harmonic distortion (THD) given by the DFT for the current injected into the electric grid is shown in Fig. 4.

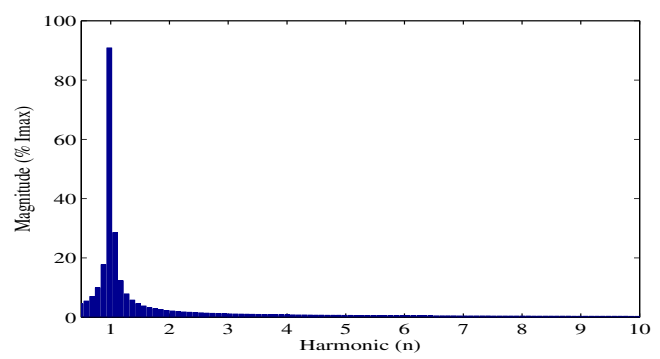

Fig. 4. Harmonics and interharmonics for the current injected into the electric grid

Fig. 4 allows concluding that the percentage of the fundamental harmonic component calculated by the DFT for the current injected into the grid has a very favorable result, about $93 \%$. Additionally, the observation of Fig. 4 is in favor that the current injected into the electric grid for the PV system with classical PI control presents a content of interharmonics relatively low and the higher order harmonics of the output current are filtered out by the second order filter.

Table 2. Data results for the Kaneka KA58 solar module

\begin{tabular}{cccccc}
\hline Parameter & $R_{s}$ & $R_{p}$ & $m$ & $I_{P V}$ & $I_{0}$ \\
\hline Kaneka KA58 & $6.28 \Omega$ & $976.02 \Omega$ & 243.08 & $1.11 \mathrm{~A}$ & $1.18 \times 10^{-6} \mathrm{~A}$ \\
\hline
\end{tabular}

The THD of the current injected into the electric grid has a very favorable result, about $2.4 \%$. Hence, the PV system with DC-DC boost and three-level power inverter topology has an adequate performance in what regards the fact that the THD of the output current is being lower than 5\% limit imposed by IEEE-519 standard.

\section{Conclusions}

Simulation studies of PV systems are essential to assist engineers not only in the design phase, but also in real-time operation where cloud-base solutions may allow enough computer resources for a better management in what regards extracting of energy, anticipating performance and deciding convenient measures to avoid malfunctions. The increased integration of PV system into the electric grids leads to technical challenges implying research for more realistic physical models able of giving a better understanding of what concerns the eventually disturbance caused by PV systems, allowing to circumvent loss of energy quality and undesirable instability problems.

The paper proposes an integrated model for PV systems linked to the electric grid through power converters. The integrated model allows a more accurate description of the dynamic of the system. The model includes a maximum power point tracking and 
power-electronic modeling for the power converters: DC-DC boost converter and the three-level convert linked to the electric grid. The control strategy used in the simulation is based on the use of classical PI controllers, PWM by SVM associated with sliding mode control and power factor control is introduced at the output of the inverter. Although more complex, this integrated model is justified for more realistic results. The application of this modeling to a case study on a-Si solar modules Kaneka KA 58 with a convenient filtering allows to anticipate that the THD for the output current is lower than the 5\% limit imposed by IEEE-519 standard for this PV system with DC-DC boost and three-level power inverter topology.

Acknowledgments. This work was partially supported by Fundação para a Ciência e a Tecnologia, through IDMEC/LAETA, Instituto Superior Técnico, University of Lisbon and by Universidade of Évora.

\section{References}

1. López, M.E.A., Mantiñan, F.J.G., Molina, M.G.: Implementation of wireless remote monitoring and control of solar photovoltaic (PV) system. In: 6th IEEE/PES Transmission and Distribution: Latin America Conference and Exposition, pp.1-6 (2012)

2. Fialho, L., Melício, R., Mendes, V.M.F.: PV system modeling by five parameters and in situ test. In: 22th SPEEDAM, pp. 577-582 (2014)

3. Rampinelli, G.A., Krenzinger, A., Chenlo Romero, F.: Mathematical Models for Efficiency of Inverters Used in Grid Connected Photovoltaic Systems. Renewable and Sustainable Energy Reviews 34, 578-587 (2014)

4. Batista, N.C., Melício, R., Mendes, V.M.F.: Layered Smart Grid Architecture Approach and Field Tests by ZigBee Technology. Energy Conversion and Management 79, 721-730 (2014)

5. Papageorgas, P., Piromalis, D., Antonakoglou, K., Vokas, G., Tseles, D., Arvanitis, K.G.: Smart Solar Panels: In-situ monitoring of photovoltaic panels based on wired and wireless sensor networks. Energy Procedia 36, 535-545 (2013)

6. Ayodele, T.R., Jimoh, A.A., Munda, J.L., Agee, J.T.: Challenges of Grid Integration of Wind Power on Power System Grid Integrity: a Review. International Journal of Renewable Energy Research 2, 618-626 (2012)

7. Raj, J.S.C.M., Jeyakumar, A.E.: A Two Stage Successive Estimation Based Maximum Power Point Tracking Technique for Photovoltaic Modules. Solar Energy 103, 43-61 (2014)

8. Fialho, L., Melício, R., Mendes, V.M.F., Rodrigues, L., Viana, S., Estanqueiro, A.: Simulation of a-Si PV system linked to the grid by DC-DC boost and two-level converter. In: 16th PEMC, pp. 934-938 (2014)

9. Seixas, M., Melício, R., Mendes, V.M.F.: Fifth Harmonic and Sag Impact with a Balancing New Strategy for Capacitor Voltages. Energy Conversion and Management 79, 721-730 (2014)

10. Giacobbe, L.: Validação de Modelos Matemáticos de Componentes de Sistemas Fotovoltaicos. Master Thesis, DEEC/IST (2005) (in Portuguese)

11. IEC 60904-1: Photovoltaic devices - Part 1: Measurement of Photovoltaic (PV) CurrentVoltage Characteristics (2006)

12. Kaneka Photovoltaic Products Information. http://www.pv.kaneka.co.jp 